Emais ainda 


\title{
QUANDO A ESCRITURA SE QUEBRA NAS ONDAS*
}

Cleonice Paes Barreto Mourão

UFMG

\begin{abstract}
RESUMO
Desviando-se da estrutura tradicional do romance, Virginia Woolf, em As ondas, põe em cena seis vozes cujas falas executam um movimento contínuo de retração e distenção movimento das ondas. As falas não estabelecem diálogo, apenas se tocam para um novo relance, revivem o passado contraído no presente e no futuro, cada uma delas marcada por pontos de intensidade, revivências que se repetem por não poderem ser substituídas. O cenário onde se desenrolam as falas é construído por uma narradora que limita o tempo ao percurso de um dia, sempre à beira-mar. Metáfora maior da escritura, o mar se derrama sobre as falas e aí produz um efeito de liquefação: desmancham-se os vetores do tempo, do espaço e das situações, para deixar na superfície a profusão de palavras que sobrenadam os acontecimentos revivenciados.
\end{abstract}

\section{PALAVRAS-CHAVE}

Virginia Woolf, As Ondas, análise textual

L'inconnu du langage reste inconnu.

Maurice Blanchot

As ondas ${ }^{1}$ não propõe uma reflexão sobre a vida, tece-a numa escritura sem começo nem fim, vozes fragmentadas e inesgotáveis em movimento de fuga. Esse sexto romance de Virginia Woolf (1931) apresenta uma arquitetura singular: composto de dez segmentos em letra diferente - o itálico -, nos quais a narradora descreve a passagem de um dia - um dia qualquer - da aurora ao poente. Nos intervalos desses segmentos, seis personagens exploram suas vivências passadas e suas possibilidades futuras através da fala como encenação dramática, sem constituir diálogos, desenvolvendo-se numa rede de monólogos que, apesar de se tocarem, nunca interagem. Cada fala entra em cena guiada pelos sentidos quando estes se debruçam sobre as pequenas criaturas - insetos, asas, folhas, grama..., ou quando se voltam à vida passada para torná-la presente como revivência, não como rememoração.

\footnotetext{
*Texto apresentado no I Colóquio LIPSI: Literatura e Psicanálise: o E da questão, realizado nos dias 6-7/9/2003.

${ }^{1}$ Woolf. As ondas. (O número da página entre parênteses, após citação, refere-se a essa edição).
} 
Nessa fala teatralizada, nada acontece: já aconteceu ou vai acontecer. Diferentemente do romance tradicional, o acontecimento só tem lugar enquanto palavra, uma palavra tecendo um emaranhado entre o imaginário e o real, entre o que verdadeiramente se passou e o que poderia ter se passado. O único acontecimento do texto é a palavra que remete a si mesma incansavelmente e ocupa toda a cena. Na verdade, o destino dos personagens está expresso em suas falas desde o início: são índices significativos, mas que, lançados na correnteza da fala, perdem seu peso de premonição; em uníssono com descrições da natureza, da vida no colégio ou da vida familiar, só na última fala de Bernard eles ganham significado: aquilo que há muito já se formava no interior das falas, mas permanecia obscuro.

\section{AS ONDAS SE INFLAM EM ALTO MAR.}

\section{Na PELE dOS SERES}

Só a linguagem poética poderia conter a dimensão voltada para o fruir do verbo em ondas ininterruptas, a cada vez diferentes, mas originadas da mesma massa fluida, o mar imenso da palavra voltada para si mesma.

Para a elaboração da linguagem poética numa obra dita "romance", Virginia Woolf se utiliza, como primeiro recurso de base, do abandono da intriga. Esta traçaria uma linha horizontal com direção determinada, o que fugiria ao propósito da obra. Complementar a esta linha, seria a linha vertical - própria do romance tradicional -, delineando os personagens com exatidão, dando a conhecer, sem falhas, aqueles que circulam no texto com função de atuantes.

Abandonando estas duas linhas - a horizontal e a vertical -, Virginia Woolf traça uma transversal móvel, capaz de recolher os tempos diversos, assim como os seres (humanos ou não), dispersos no universo de sua ficção, sem nenhuma preocupação de organizá-los em sistemas ou categorias, ou seja, sem a intenção de construir sínteses. Trata-se do encontro com os seres no júbilo provocado pela percepção e pela sensação, não pelo saber. Este último eliminaria das coisas animadas e inanimadas sua gratuidade, seu dom de se doar inteiramente aos nossos sentidos.

"Eu tiro a substância até certo ponto por não confiar na realidade”. ${ }^{2}$

Paradoxalmente, é pela constante e minuciosa exploração da superfície que Virginia Woolf escava uma profundidade, realizando em sua ficção a célebre asserção de Valéry: "o mais profundo é a pele". ${ }^{3}$ Percorrendo a pele das coisas e da natureza, a escritura realiza um processo de planificação, destruindo os segredos, libertando a caverna de sua escuridão, desfazendo os nós das subjetividades.

A permanência no sensível não é, de modo algum, uma etapa que prepararia o acesso ao não sensível, ao conhecimento para além dos limites das cores, das folhas, das borboletas, das formas das nuvens. A exploração do sensitismo, atividade comum a todas as falas,

\footnotetext{
${ }^{2}$ Woolf. Os diários de Virginia Woolf, p. 98.

${ }^{3}$ Valery, Paul. Cit. por Gilles Deleuze. Lógica dos sentido, p. 11.
} 
porque expressa a mesma experiência de vida e de mundo, torna secundário o emissor que se perde numa rede cujas linhas se conectam com outras redes e permitem uma experiência compartilhada. Daí o intercâmbio entre os nomes que atuam na fala: "disse Rhoda", "disse Louis", “disse Bernard” etc. A indicação do nome, na realidade, não nomeia, apenas pontua o deslizamento, assinala o agente de um determinado ato de fala.

"Os seis personagens evoluem num espaço indeterminado, passam diante de nossos olhos como um desfile de sombras, no qual ora um ora outro se destaca para desfiar num longo recitativo o conteúdo do fluxo interior que se desenrola na consciência”. ${ }^{4}$

Esse "espaço indeterminado" se deve, em grande parte, à utilização reiterativa do termo comparativo "como", instaurando uma dimensão suplementar:

"Como" e "como" e "como" - mas qual é a coisa que jaz debaixo da aparência da coisa?" (p. 121), diz Rhoda, a inquieta jovem sempre tentando ler o desenho das pétalas na bacia de água, arriscando-se no mais além do dito.

"O mar não se distinguia do céu, exceto por estar um pouco encrespado, como um tecido enrugado." (p. 7)

"A onda parava, partia novamente, suspirando como um ser adormecido." (p. 7)

"Aos poucos, a faixa escura no horizonte clareou como se a borra numa velha garrafa de vinho se tivesse acomodado" (...) (p. 7)

O emprego desse comparativo é predominante nos entreatos, abrindo o espetáculo do dia na cena e nos bastidores. $\mathrm{O}$ mesmo procedimento ocorre na fala dos personagens, quando a reiteração do "agora" e do "vejo" desloca o real na direção do imaginário, constrói um universo virtual.

O termo comparativo tem como efeito desmanchar o tecido da vida real e trazer à tona sua substância virtual. A vida se escoando na torrente de palavras, na profusão de metáforas e comparações, nunca ela mesma, mas a sua fragrância, não os seres em si mesmos, mas a sua franja espumante, trabalho do tempo e da memória que só se torna possível no interior das conotações produzidas pelo poético. Retirando a vida de sua grade de acontecimentos, As ondas recupera toda sua complexidade; tirando-lhe a casca, seu caroço surge na substância da escritura desenraizada, resistente às grandes verdades e às frases ordenadas segundo um referencial inquestionável.

\section{Vozes espumas bReVES SE ESPALHAM NA PRAIA-ESCRItURA.}

\section{Os entreatos}

A linguagem poética de As ondas tem como metáfora maior o mar e as ondas. Nos segmentos em itálico, quando a narradora assume explicitamente sua função, descrevendo o dia, a imagem do mar é a dominante. $\mathrm{O}$ comando desse dia que amanhece cabe à figura de uma mulher:

\footnotetext{
${ }^{4}$ Nathan. Virginia Woolf, p. 11.
} 
"Ao fundo, também o céu se fez translúcido, como se ali baixasse um sedimento branco, ou como se o braço de uma mulher deitada sob o horizonte erguesse uma lâmpada e faixas brancas, verdes e amarelas se espraiassem pelo céu como as varetas de um leque. Depois, a mulher ergueu a lâmpada mais alto, e o ar pareceu tornar-se fibroso, apartando-se da superfície verde, bruxuleando e chamejando em fibras vermelhas e amarelas, como flamas enfumaçadas que se alçam de uma fogueira". (p. 7)

Inegável a presença metafórica da narradora iluminando o palco onde vão atuar, nas páginas seguintes, os três homens e as três mulheres, também eles "enfumaçados", "bruxuleando" sua fala inesgotável.

Poesia em prosa, os entreatos acumulam metáforas que recobrem o fazer artístico de As ondas. Assim, o movimento contínuo de relance das falas surge na imagem das ondas:

"As ondas quebram-se, esparramando agilmente suas águas sobre a praia. Uma após outra amontoavam-se e desabavam, com a força da queda os respingos voltavam-se sobre si mesmos" (p. 111)

O mesmo mar, as mesmas ondas, em imagens recorrentes, mas diferentes sob a luz do sol que se desloca em direção ao poente:

"As ondas rufavam na praia como guerreiros com turbantes, como homens com turbantes, que brandiam suas azagaias envenenadas sobre suas cabeças, precipitandose ao encontro dos rebanhos de ovelhas brancas" (p. 57-58)

"... e o mar que batia como um tambor a chamar um regimento de soldados com suas plumas e turbantes.” (p. 82)

Esse mar inaugural se derrama sobre a fala dos atores e aí produz um efeito de liquefação: desmancham-se os vetores do tempo, do espaço, de situações, para deixar na superfície a profusão de palavras que sobrenadam a realidade. A presença do mar se expande, ultrapassa os segmentos que descrevem o percurso do dia e contamina todo o texto que se torna um movimento contínuo de palavras-ondas recobrindo a vida, ininterruptas, afogando tudo na sua matéria caudalosa.

Palavras-ondas que se formam da mesma massa líquida num movimento uniforme, e, no entanto, a cada vez diferente. Entre a voz da narradora e a voz dos personagens, e entre estas vozes mesmas, o perpétuo movimento de retração e expansão. Nesse ondular constante, instalam-se vazios, brechas ou concavidades suficientemente largas para comportar o que a palavra não diz, ou diz apenas na espuma que se faz quando a palavra se cala.

\section{NASCE dA FORÇA DA RETRAÇÃO A VIOLÊNCIA DAS ONDAS.}

Recursivas também nos entreatos são as passagens que focalizam os pássaros. Ousaria sugerir que elas remetem às vozes que ocupam a maior parte do texto:

“... os pássaros cantavam separadamente (...) Cada um cantava com estridência, com paixão, com veemência, como a deixar o canto rebentar, não importando se fragmentasse o canto de outro pássaro numa áspera dissonância.” (p. 82)

“... havia medo no seu canto e suspeita de dor, e também a alegria que se extrai rapidamente do instante". (p. 56) 
Sem levar em conta o que é dito e verificando como as falas se desenrolam - sem avançar na direção de uma intriga -, percebe-se que, na verdade, a fala de um personagem se quebra inesperadamente diante da voz de comando do diretor de cena: "Disse"... que introduz outra fala sem conexão com a precedente, ou tocando-a numa relação assindética. Embora ocupando a mesma cena, as vozes cantam separadamente em solos na clave própria das experiências e anseios de cada uma. E deixam o canto "rebentar" sem se exaurir. Mas uma "camaradagem" tem lugar ao longo de todo o texto, até que a voz de Bernard fica sozinha em cena e relata - ele, o único que sabe fabricar histórias - o destino de cada um.

Mas há um pássaro sem voz: Percival, "magnífico como um comandante medieval"(p. 29). E, no entanto, seu silêncio é força de atração, ou ainda, se prosseguirmos com a metáfora musical, seu silêncio pode ser percebido como a batuta do maestro regendo vozes que em tom menor cantam a dor de sua ausência. Seu vôo para a Índia e sua morte, ao invés de anulá-lo, projeta sua sombra sobre os demais.

\section{Percival - mar em ressaca.}

\section{PONTOS DE INTENSIDADE}

A entrada da fala de cada personagem é invariável: "disse", seguindo-se o nome do personagem. Sempre o mesmo verbo, na mesma modalidade temporal. Esse recurso produz sobre cada fala um efeito de nivelamento, de equilíbrio entre todas elas, não permitindo uma intensidade maior numa ou noutra. "Disse", simplesmente o verbo, o ato de dizer, desprovido de qualquer atributo que expressasse a tensão ou distensão da fala, esse recurso estilístico confirma a voz como agente único e soberano do texto. $O$ ato de dizer, apresentado assim em sua nudez, afeta o discurso, encobrindo-o de um equilíbrio tão perfeito em relação a si mesmo e aos demais, que é em surdina que se ouve por trás do "disse" o grito de tantas vivências. Ouve-se em surdina "a grande besta [que] pateia na praia", na obsessão de Louis; a cantiga abafada da eterna canção de ninar de Susan: "dorme", "dorme"; o urro do tigre de Rhoda, quando salta sobre a andorinha; o galope das palavras do poeta Neville; a respiração lasciva do corpo sedutor de Jinny; a gota de tempo que tomba sobre Bernard. Tudo isso é dito, mas a uniformidade com a qual cada dito entra em cena, retira-lhe todo pathos. E, no entanto, este se faz de uma presença sem tréguas. As entranhas do "disse" guardam, na sua indiferença e uniformidade, aquilo que a escritura expressa na sombra:

"faltam palavras para a dor. Deveria haver gritos, rachaduras, fissuras..." (p. 196)

E acrescento: disse Virginia Woolf.

O "disse" introduz cada fala em tom menor e é nesse menor que se ouve - com maior nitidez - a pungência de uma dor maior.

Cada voz traz consigo um ponto de vibração própria que marca a fala com uma singularidade única. Para cada agente da fala há um núcleo - o ponto de vibração - que se repete e que não pode deixar de se repetir, porque é a energia que propulsiona a fala e sem a qual ela se paralisaria. 
Um breve levantamento confirma a função dos temas recursivos para cada ato de fala. Para Louis, são suas raízes, as mulheres que levam cântaros vermelhos até o Nilo, e a besta que pateia na praia:

“e a besta acorrentada pateia na praia. Pateia sem parar “ (p.45)

"e começo a sentir terra firme sob meus pés, minhas raízes descendo, descendo até se enroscarem em torno de algo duro no centro." (p.27)

"vi mulheres carregando cântaros vermelhos junto ao Nilo". (p.72)

Rhoda sempre lamentando a ausência do rosto próprio: "não tenho rosto". Afirmação que atua na superfície indiferenciada da fala, até que um dia age na superfície espelhada do rio no qual ela mergulha no ato definitivo. O tema da água, recorrente em Rhoda, é índice de seu destino:

"Quero arrancar-me dessas águas. Mas elas se amontoam sobre mim, arrastam-me por entre seus ombros enormes; reviram-me, sacodem-me; fico estendida entre essas longas luzes, essas longas ondas..." (p. 22)

"Cavalgo sobre as águas e afundarei sem ninguém que me salve".

Andorinha enfrentando um tigre que, no seu salto, leva-a "do outro lado do mundo". Susan, a mulher do campo, da "felicidade natural", do cuidado com seus pombos e seu esquilo; a presença do pai com suas perneiras e seu velho chapéu, sua inacabável canção de ninar, mas também seu ódio e amor:

"Embora minha mãe tricoteie meias brancas para mim e faça bainha em aventais e eu seja uma criança, amo e odeio." (p. 13)

"Lá está meu pai de costas falando com um fazendeiro (...) Lá está meu pai de perneiras. Lá está ele.” (p. 48)

"Odeio linóleo; odeio pinheiros e montanhas". (p. 74)

"As únicas palavras que compreendo são gritos de amor, ódio, fúria e dor". (p. 98)

Os vestidos brilhantes de Jinny, as festas, os salões, o corpo sedutor:

"Meu corpo vai diante de mim como uma lanterna em um relvado escuro, extraindo das trevas uma coisa após outra, para um círculo de luz." (p. 96)

Os pilares exaustivos de sua fala deslizando sobre outros temas, mas sempre ancorados no corpo erótico.

"É por isso que o amo", diz Neville, referindo-se a Percival; amor que pontua sua fala, a isso acrescentando-se o desejo de fazer poemas. Neville e suas constantes interrogações sobre os atos mais corriqueiros:

..."devemos sentar dentro de casa contemplando os carvões em brasa? Devemos estender nossas mãos para livros e ler uma passagem aqui, outra ali? Devemos gritar de tanto rir, sem motivo?" (p. 105)

Quanto a Bernard, sua fala gira em torno de dois temas dominantes: o tempo e a escritura: escrever histórias: 
"Eu, porém, se estou com outras pessoas, as palavras logo formam anéis de fumaça - vejam como imediatamente as frases começam a fluir em espirais dos meus lábios." (p.52)

"Contudo, uma boa frase parece-me ter existência independente (...) eu que vivo a chapinhar em meio a palavras mornas, solúveis." (p.53)

"E o tempo deixa tombar sua gota (...) A gota que se formou no telhado da alma despenca. Condensando-se sobre o telhado da minha mente, o tempo deixa tombar sua gota." (p.136)

"Essa gota caindo é o tempo afilando-se num ponto." (p.137)

A repetição denuncia a natureza da linguagem poética, "em que cada termo, insubstituível, só pode ser repetido". ${ }^{5}$ Não se trata, aqui, de uma repetição mecânica: emergindo em situações diversas, ela pontua algo de originário que, por trás do mesmo, se faz diferente a cada vez, pranto inacabável sobre aquilo que a palavra não pode conter. Daí o deslizamento incessante da repetição eclodindo no inesperado, incapaz de fazer representação, indigente de substituições, aprisionada no relançamento.

Em As ondas, essas repetições não são relatadas nem rememoradas, mas exibidas em ato pela força da voz, sendo esta da ordem do acontecimento. Assim, cada repetição é acontecimento, é o mesmo renovado e re-apresentado, nunca representado. A repetição é o fio que costura os pedaços do ser dispersos na linguagem; expressão do que é inalterável, nódulo incorruptível através do fluxo-rio da linguagem; lugar primordial para onde se volta sem cessar a fala, porque ali está sua fonte, ponto mudo de gozo da escritura.

As reincidências nas falas dos personagens e nos entreatos constituem pontos de relance para o deslizamento da escritura, sem, contudo, significar um avanço no sentido de progressão de um tema. Sem estarem presos a um começo, esses pontos surgem a qualquer momento, cortam a escritura aleatoriamente. Não se fazem pontos de partida, mas de intensidade, responsáveis pelo pathos muito mais da escritura que da vivência dos personagens, uma vez que esta deixa de ser a expressão de uma individualidade para perderse na multiplicidade das falas, por sua vez, intercambiáveis.

Inseridos nas linhas de fuga, os pontos de intensidade permitem o cruzamento destas para a formação de redes. Uma vez constituintes da rede, eles se dissolvem, naufragam na profusão da escritura, mas não deixam de assombrá-la revelando a vocação maior do texto woolfiano: a paixão nodular que se expressa na banalidade dos gestos mais cotidianos, do olhar agudo sobre as coisas; uma superfície indiferenciada, e aparentemente anódina, revelando as cicatrizes dos seres.

\section{A ONDA É O SUSTO dO MAR CALMO.}

\section{O PULSAR DA ESCRITURA}

A metáfora da onda atua igualmente na questão do tempo. Em As ondas, não se trata do tempo fora dos gonzos, mas de um tempo contraído; nele as modalidades de

${ }^{5}$ Deleuze. Diferença e repetição, p. 22. 
passado e futuro estão presentes, mas de uma presença muito especial: mergulhadas nas águas densas da linguagem poética, de onde emergem encharcadas de tudo aquilo que envolve os fatos, de modo a só deixar presente o efeito dessas modalidades, isto é, o efeito do passado, o efeito do futuro, quando as águas se quebram em ondas e os diversos tempos são apenas a espuma que inunda o presente - o presente da fala em ato, da rememoração tornada acontecimento, do futuro presentificado. A palavra em ato traz à cena o passado; por não se tratar de rememoração, essa palavra está livre da ordem cronológica; qualquer recorte do passado, seja ele mais longínquo ou mais próximo, ocupa a cena com um valor de dramaticidade; o mesmo processo se dá com relação ao futuro: ele não significa um projeto, mas aquilo que pode acontecer, uma possibilidade, pois colocada no mesmo registro de tempo flexível e desancorado da passagem ordenada dos dias.

Não se pode dizer que a cronologia tenha sido inteiramente afastada do texto. Sempre acompanhando a metáfora do mar, o tempo cronológico é como a onda quando ela se forma ainda longe da praia, no bojo profundo das águas; só na última fala, a de Bernard, é que ela se arrebenta e joga na praia o destino já então cumprido de cada personagem. "As ondas quebraram na praia", assim termina o texto.

A memória atua como conexão das diferentes modalidades de tempo, deixando-as, contudo, livres de Cronos, trazendo-as à tona como espetáculo.

A expressão "agora”, exaustivamente recursiva, introduz muitas vezes a fala e funciona como uma flecha que perfura o tempo e reúne as camadas de passado e futuro, numa só espessura porosa. $O$ toque do "agora", marcação de um pulsar, ressalta a função da palavra como referencial de si mesma, não remetendo a acontecimentos fora dela. A partícula aparentemente temporal ultrapassa essa função e age na criação de um imaginário independente da marcação do tempo.

O "agora" acrescenta ao gesto da escritura o gesto da leitura, trazendo o leitor para o interior da ficção. O que importa é o que se está lendo no momento, no "agora”, leitura encerrada no círculo da palavra. Para além desta, a referência se esgarça, sem se anular de todo, constitui uma névoa da qual o leitor não pode sair. A pontuação do "agora" deslocase do instante presente e se torna pulsação da escritura e da leitura.

Enfim, o "agora" delineia a gota de tempo, apenas a gota:

"E o tempo deixa tombar sua gota - disse Bernard. A gota que se formou no telhado da alma despenca. Condensando-se sobre o telhado da minha mente, o tempo deixa tombar sua gota." (p.136)

"Essa gota caindo é o tempo afilando-se num ponto." (p.137)

Essa gota de tempo contém os instantes de intensidade que marcam singularmente a escrita de Virginia Woolf. Não se trata de uma revelação, algo que viesse completar o vazio do ser ou responder a questões existenciais. Simplesmente momentos privilegiados quando, diante de um objeto - uma lagarta, um pedaço de cortina, a luz iluminando um prato na mesa da cozinha -, acontece o júbilo da comunhão com o mundo sem a interferência da razão, apenas no gozo dos sentidos.

O termo "agora" é complementado pelo uso também recursivo de "vejo". Mas tratase de um olhar que transforma a recordação em ato: fazendo a passagem do virtual ao atual, ele destrói o intervalo temporal que separa o passado e o futuro do presente. $\mathrm{O}$ 
presente da escritura é o ponto de contato entre o passado e o futuro, um ponto que provoca o fluir da palavra. Nada se passa no presente a não ser a própria escritura, ou melhor, a voz-escrita.

O contraponto desse processo são os entreatos da narradora, nos quais o presente da escritura coincide com o presente relatado, ou seja, com a descrição do desenrolar do dia.

\section{AS ONDAS SE QUEBRAM TEMPO AFORA.}

\section{A SOLIDÃo de BERNARd}

Nas falas intercaladas dos seis personagens, vozes em ato, predomina o tempo presente contendo o passado e o futuro. Nessa contração do tempo, circulam as experiências dos personagens, apresentando um paradoxo: quanto mais falam de si mesmos, menos corporificados os percebemos. Todo o ser reflui para a superfície da escritura elaborada na abundância de palavras, na sofreguidão de dizer tudo. Assim, como que abstraídos do próprio corpo, eles revelam que é na palavra - falada - que todo o corpo se joga, não um corpo passível de descrição - como os personagens de romances tradicionais -, mas um corpo que ganha forma e solidez na voz, o instrumento do ser capaz de arrancar de suas profundezas aquilo que o constitui e que só pode ser substituído pelo "grito" ou pelo "gemido".

O deslizamento enlouquecido de uma voz a outra interrompe-se quando o entreato da narradora anuncia a noite:

"O sol declinara. Não se distinguiam mar e céu. As ondas ao quebrarem, derramavam na praia seus leques alvos, enviavam alvas sombras para o recesso das cavernas sonoras, depois rolavam de volta, suspirando por sobre as pedras" (p.175)

Nesse momento entra em cena apenas uma voz: a de Bernard. Enquanto na fala dos seis personagens predominam as modalidades de passado e futuro contraídas no presente, a fala de Bernard mergulha na noite do passado. Sua voz é uma espécie de "caverna sonora". Bernard é aquele que vinha se anunciando, ao longo do texto, como o "construtor de frases", o único habilitado a elaborar uma história, embora saiba que esta não tem começo nem fim, que só se faz enquanto perdurar o entrechoque das falas, porque é por aí que a vida passa. Significativa uma das primeiras falas de Bernard:

"Olhem a teia de aranha no canto da sacada" (...) (p.8)

Metáfora do próprio personagem encarregado de tecer a teia com os fios que cada um dos amigos lança na fala e, com eles, construir a história. Tecelão que se interroga sem cessar sobre sua missão:

... "preciso contar-lhe uma história - e há tantas, tantas: histórias de infância, histórias de colégio, amor, casamento, morte, e assim por diante; e nenhuma delas é verdadeira. (...) Além disso desconfio dos nítidos desenhos da vida lançados sobre meias folhas de papel de carta". (p.177) 
E ainda:

... "de que adianta elaborar penosamente essas frases coerentes, quando precisamos não de uma seqüência coerente, mas de um latido, um gemido?” (p.186)

"Mas faltam palavras para a dor. Deveria haver gritos, rachaduras, fissuras”... (p.196)

"A vida talvez não seja suscetível de ser tratada como o fazemos ao tentar relatá-la".

Bernard toma o lugar da "dama sentada à escrivaninha, escrevendo" (p,185), visão que ele registra várias vezes. Embora se trate de uma palavra-falada, sua voz está muito mais do lado da palavra-escrita. Não porque esteja fazendo um relato, mas porque seu propósito é recolher o passado e lhe dar um abrigo seguro na escritura. Não mais a palavra em ato, mas em rememoração. Enquanto as vozes de seus companheiros tecem a vida na palavra oral - sempre ameaçada de desaparecimento -, a dele pretende "explicar", num relato. Mas nem por isso sua palavra-escrita - apesar do disfarce do ouvinte a quem ele se dirige - torna-se lógica, contínua. É ainda a escritura fragmentada, lacunar e repetitiva, e é somente assim que ele pode resgatar um passado e um futuro anterior que foi todo elaborado na palavra oral, quebradiça e repetidora. A fragmentação da escrita coincidindo com o despedaçamento do eu pulverizado na proliferação das palavras. É assim que o resgate se faz mais autêntico. Então, a mudança de registro se dá apenas no lugar de onde parte sua palavra: o passado. Trabalho de luto em relação a si mesmo - Bernard é agora um senhor de cabeça grisalha, como também em relação aos seus companheiros: Rhoda e Percival estão mortos; Susan, Jinny, Neville e Louis afastados do convívio que os unia no passado.

Foi preciso o silêncio de seus companheiros - "caverna sonora" - para que Bernard pudesse construir a história anunciada desde o início. Mas silêncio relativo, no qual a voz dos cinco amigos se faz ouvir como sussurros longínquos, afastada da cena aberta, agindo nos bastidores da memória de Bernard. A noite anunciada no entreato que antecede o monólogo de Bernard é a sua solidão, assombrada pelos fantasmas - vozes que agora só habitam o passado.

Para ser coerente na construção de sua história, Bernard deve perfazer o mesmo caminho: o da linguagem poética que só significa numa segunda dimensão, sendo a primeira o fruir de um verbo que, neste momento, não pertence apenas a Bernard, mas a todas as outras vozes, no movimento de resgate feito por ele. Nesse gesto, revela-se a secundariedade do agente da fala, para prover a palavra de uma soberania que só a linguagem poética pode lhe fornecer. Os agentes múltiplos - Susan, Rhoda, Jinny, Neville, Louis - desaparecem por trás do único agente Bernard, o leitor do passado, o escrivão das experiências por ele registradas no cartório da memória e da palavra-escrita.

$\mathrm{Na}$ tarefa de resgatar o passado, Bernard se debate na passagem do tempo e, repetidamente, como numa ladainha melancólica, afirma a inexorabilidade dessa passagem:

“Terça vem depois da segunda; depois vem quarta." (p.191)

"Terça-feira segue a segunda; quarta a terça." (195)

"Depois da segunda vem a terça." (199)

"Depois da segunda-feira vem a terça e segue-se a quarta." (202) 
A história construída por Bernard não se prende, contudo, nessas grades. O tempo cronológico, martelando nas têmporas de Bernard: é contra ele, ou acima dele, que Bernard lança suas frases, mesmo sabendo de sua impotência:

... "de que adianta elaborar penosamente essas frases coerentes, quando precisamos não de uma seqüência coerente, mas de um latido, um gemido?” (p. 186)

Não importa o que é dito, o dizer poético é sempre da ordem do gemido. Não é a reconstituição do passado, contudo, que promove a consistência da vida de Bernard - no caminho inverso ao de Proust - nem a de seus amigos. A trajetória cronológica que ele tenta em sua fala se submerge na força propulsora da palavra sempre escapando do tempo de direção única, relançando-se para trás e para a frente, indiferentemente, submissa apenas ao prazer de seu próprio labor. Nessa rede frouxa de palavras que não estancam o tempo, a vida tampouco se estanca - a vida das palavras.

A passagem da palavra-voz para a palavra-escrita, no monólogo de Bernard, revela o deslizamento da escritura woolfiana que, em registros diversos, conserva o mesmo fruir da palavra tecendo-se no inacabável, perdendo-se para se achar. Para interromper o movimento infindável das ondas, num ponto qualquer, Virginia Woolf corta o fio da escritura que nutria esse universo de palavras - e termina:

"As ondas rebentaram na praia.". (p. 222)

\section{4}

\section{RÉ S U MÉ}

En s'écartant de la structure traditionnelle du roman, Virginia Woolf, dans The Waves, met en scène six voix dont les discours, tels les ondes, réalisent un mouvement continu de rétraction et de distension. Les paroles ne créent pas de dialogues, elle ne font que se toucher en vue d'un nouveau relancement; elles revivent le passé, resserré dans le présent et dans le futur, chacune e'entre elles marquée par des points d'intensité, des vécus qui se répètent dans l'impossibilité d'être substitués. Le décor où se déroulent les discours est construit par une narratrice qui réduit le temps à une journée, toujours au bord de la mer. Métaphore majeure de l'écriture, la mer déborde sur les discours en y produisant un effet de liquéfaction: les vecteurs du temps, de l'espace et de situations s'effritent, en laissant à la surface la profusion de mots qui flotent sur les événements re-vécus.

\section{MOTS-CLÉs}

Virginia Woolf, The Waver, analyse textuelle 


\section{REFERÊNCIAS BIBLIOGRÁFICAS}

Deleuze, Gilles. Diferença e repetição. Trad. Luiz Orlandi, Roberto Machado. Rio de Janeiro: Graal, 1988.

Nathan, Monique. Virginia Woolf. Trad. Léo Schilafman. Col. Escritores de sempre. Rio de Janeiro, José Olympio, 1989.

Valery, Paul. Cit. por Gilles Deleuze. Lógica dos sentido. Trad. Luiz Roberto Salinas Fortes. São Paulo: Perspectiva, 1974.

Woolf, Virginia. As ondas. Trad. Lya Luft. 3. ed. Rio de Janeiro: Nova Fronteira, s/d.

Woolf, Virginia. Os diários de Virginia Woolf. Trad. J. Antônio Arantes. Edição Anne Olivier Bell. São Paulo: Companhia das Letras, 1989. 